\title{
Deux parutions récentes de musique des Caribs
} noirs

\section{Michel Plisson}

\section{(2) OpenEdition}

\section{Journals}

Édition électronique

URL : http://journals.openedition.org/ethnomusicologie/832

ISSN : 2235-7688

\section{Éditeur}

ADEM - Ateliers d'ethnomusicologie

Édition imprimée

Date de publication : 1 novembre 2002

Pagination : 227-228

ISSN : 1662-372X

Référence électronique

Michel Plisson, « Deux parutions récentes de musique des Caribs noirs », Cahiers d'ethnomusicologie [En ligne], 15 | 2002, mis en ligne le 11 janvier 2012, consulté le 22 avril 2019. URL : http:// journals.openedition.org/ethnomusicologie/832

Ce document a été généré automatiquement le 22 avril 2019

Tous droits réservés 


\title{
Deux parutions récentes de musique des Caribs noirs
}

\author{
Michel Plisson
}

\section{RÉFÉRENCE}

Honduras: Musique garifuna : la tradition des Caribs noirs. Enregistrements, textes et photos : Cyril Vincensini et Andrae Romay. 1 CD Inédit/Maison des cultures du monde. W 260102, 2001.

Ensemble Wabaruagun : Chants des Caribs noirs. Enregistrements, textes et photos : Cyril Vincensini et Andrae Romay. 1 CD Ocora C 560162, 2002.

1 L'extraordinaire histoire des Garifunas commence à être un peu mieux connue depuis la publication récente de plusieurs articles et CDs sous différents labels, notamment ceux du groupe The Original Turtle Shell band paru, l'un chez Stonetree Records, l'autre chez Mélodie ; la venue de ce groupe en France à plusieurs reprises y a aussi contribué à faire connaître cette musique. Mais la musique des Caribs noirs ne se réduit pas à un seul groupe musical. Il s'agit d'une tradition qui s'est constituée sur cinq siècles. Son histoire a été retracée à plusieurs reprises dans différentes publications dont un article dans les Cahiers (Penedo \& D'Amico 2000). «Leur histoire est née d'un naufrage », comme le dit Cyril Vincensini, l'auteur, concepteur, photographe et preneur de son de ces deux magnifiques albums dont il est difficile de dire lequel est meilleur que l'autre, si toutefois cette question a un sens.

Deux navires négriers espagnols coulent au XVII ${ }^{\mathrm{e}}$ siècle sur les récifs de l'île de St.Vincent, dans les Petites Antilles. Les survivants sont recueillis par les Indiens Caribs, à la réputation féroce, chez lesquels ils vont s'intégrer, apprendre leur langue (sans doute au départ lengua franca permettant de communiquer au delà des multiples langues africaines parlées par les naufragés survivants), épouser leurs femmes et adopter leurs coutumes comme les peintures corporelles faites avec le roucou et la déformation crânienne. Des 
Français, avec qui ils commercent et créent des alliances, ils retiendront la manière de compter (jusqu'à aujourd'hui ils utilisent le terme " demi-cent » pour désigner le chiffre cinquante). Les Anglais, qui luttent pour l'hégémonie dans la région, les déporteront plus tard au large du Honduras, d'où ils essaimeront le long des côtes du Guatemala, du Belize et du Honduras. Aujourd'hui, les quelque 300000 Garifunas se répartissent sur ces territoires avec une bonne partie à New York et Los Angeles, et, comme de nombreux Latino-américains dans ou hors de leur pays, ils souffrent du chômage. Toutefois, leurs traditions restent étonnamment vivaces comme on peut s'en rendre compte à l'écoute de ces deux excellents albums réalisés par l'auteur après plusieurs séjours de plusieurs mois chez les Black Caribs.

Les musiques étonnent par leur vitalité, la force de l'expression musicale, la qualité des interprètes, l'originalité des mélodies et la complexité des rythmes sur lesquels elles se construisent. Alors que l'on pourrait penser à une parenté musicale, à un «air de famille» qui les rattacheraient à la musique des groupes afro des Antilles : Haiti, Cuba, Porto-Rico, Costa-Rica, voire aux musiques afro de la partie sud du continent : Colombie, Venezuela... relativement proches géographiquement, on constate une indiscutable originalité, ce qui n'est pas le moins intéressant de cette musique. Certes, ces musiques appartiennent sans conteste à l'univers afro-latino-américain. On y retrouve l'opposition entre soliste et chœur responsorial, l'hégémonie des modes pentatoniques descendants autorisant parfois des degrés mobiles, le jeu des tambours excluant ici l'usage des instruments à cordes, pourtant omniprésents en Amérique Centrale. Mais, au delà de ces persistances, il existe des différences marquées dont il faudra tôt ou tard décrypter l'arcane.

En attendant les réponses à ces questions, on éprouve un grand plaisir à l'écoute de ces deux albums. Chacun contient des chants correspondant à des rituels différents, chantés surtout par les femmes. Le disque Inédit contient des chants funèbres, dits aussi novenario car le rituel dure neuf jours, et des chants qui accompagnent le rituel dügü dans lesquels interviennent les chamanes et des jeux de tambours complexes. On appréciera aussi les chants pratiqués pour la préparation du manioc (yuca), aliment de base des populations tant afro qu'amérindienne. L'africanité est aussi très forte dans le disque Ocora, notamment dans ces magnifiques chants de la danse adügürahani accompagnés par la conque marine, laquelle représente la lente progression des ancêtres, emprunt aux cultures amérindiennes des Antilles, comme les lamentations a cappella abamahani, réputées notamment pour apaiser la douleur et utilisées pour leurs vertus thérapeutiques lors des rites funéraires. Le chant gunchei, que la tradition rattache à la période de St.Vincent selon ce qui fut rapporté à l'auteur ${ }^{1}$, ouvre encore un univers différent. Si, durant les rituels, ce sont surtout les femmes qui chantent, en revanche les chants et rythmes de parranda, à caractère nettement plus profane, dans lesquels intervient la percussion des carapaces de tortue - dont le son rappelle étrangement le teponatzli mexicain - reste le terrain privilégié des hommes. La bonne qualité technique des enregistrements et le livret bien documenté agrémenté de quelques photos des chanteuses, viennent renforcer encore l'intérêt de ces deux albums. 


\section{BIBLIOGRAPHIE}

PENEDO Ismael et Leonardo D'AMICO, 2000, « La culture musicale des Garifuna : Communauté afro-amérindienne d'Amérique centrale ». Cahiers de musiques traditionnelles 13, " Métissages » : 64-75.

\section{NOTES}

1. L'émission "Les chemin de la musique », de France culture, a réalisé avec Cyril Vincensini cinq programmes consacrés aux Garifuna, diffusés du 10 au 14 juin 2002. 